Egyptian

Orthodontic Journal

\title{
EVALUATION AND MANAGEMENT OF PAIN RELATED TO ORTHODONTIC TREATMENT
}

\author{
Nahla E Gomaa ${ }^{1}$ MD, Mohammed M Ellaithy ${ }^{1}$ MD \\ ABSTRACT:
}

The aim of the study was to evaluate the onset and intensity of pain induced after the insertion of fixed orthodontic appliances. Also, to compare analgesics versus non-analgesics pain management approach (protocols). Material and methods: One hundred and fifty patients, ranged from 13 to 22years of age were asked to answer a questionnaire previously prepared to fulfill the aim of this work. They were divided into three groups, 50 patients each: the first group was the control group. They used acetaminophen $500 \mathrm{mg}$ orally when pain was felt (VAS $\geq 4$ ). The second group was asked to use acetaminophen $500 \mathrm{mg}$ orally 30 minutes before the procedure and the third group was asked to use bite wafer. Results: Results of this study revealed that there was a significant difference in pain intensity between group I and the other two groups in the first 24hrs. Pain intensity was high in group I compared to groups II and III. While, comparison between group II and group III revealed non-significant difference $(p>0.05)$. Time to first analgesia was significantly shorter in group I compared to either group II or III. While, comparison between groups II and III revealed non-significant difference. Analgesic consumption in group I was significantly bigger than the other two groups, with non-significant difference between these two groups. Conclusion: Either preoperative analgesia or bite wafer can effectively relief post-operative pain during orthodontic treatment.

1- Lecturers of Orthodontic, Faculty of Dentistry, Tanta University, Egypt. 
Egyptian

Orthodontic Journal

\section{INTRODUCTION}

Pain is viewed as one of the significant fears and anxieties of patients preceding orthodontic treatment ${ }^{1}$. Pain and inconvenience are frequent reactions of orthodontic treatment with fixed appliances. The orthodontist ought to have the capacity to educate his patient about the regular reaction or side effect of treatment, particularly before the fixed orthodontic appliances ${ }^{2}$.

Pain is a subjective reaction to stimulus that is entirely variable relying upon the individual, and depends upon numerous things, for example, age, sexual orientation, cultural contrasts and past encounters. Pain likewise incorporates sensations evoked by and responses to harmful stimuli. It can be depicted or described by orthodontic patients as a feeling of tension, pressure, throb (ache) and soreness of teeth ${ }^{3}$.

There is an extensive variety of individual reaction to pain even when comparable forces are applied to tooth. The subjective view of pain is hard to measure. Two hours after use of orthodontic force, the pain intensity usually increases bit by bit to reach a peak level at 24 hours, and diminishing of that pain by the seventh day ${ }^{4,5,6}$.

Mechanism of pain after orthodontic force application is not understood. It is suggested that the changes in blood flow of periodontal ligament are the cause of these perceptions ${ }^{7}$.

Response of pain can be classified into three different degrees:

First degree pain: heavy force is applied on the tooth with an instrument in the same direction as the fixed appliance. The patient is not aware of this pain till orthodontist effectively manipulates the teeth to be moved with the appliance.

Second degree pain: the patient has the ability to masticate normal diet with no difficulty, but during tooth clenching or heavy biting pain or discomfort appears.

Third degree pain: is characterized by spontaneous pain during mastication of food with normal consistency. Pain can also be classified into immediate and delayed pain. Immediate pain occurs when there is 
Egyptian

Orthodontic Journal

initial compression of periodontal ligament, while delayed pain appears few hours later, large range of force value is induced with hyperplasia of ligament ${ }^{8}$.

Distinctive strategies have been developed to alleviate pain. These techniques include: low-level laser treatment to periodontal tissues, transcutaneous electrical nerve stimulation. Additionally, some degree of pain control by vibratory stimulation of periodontal ligament has been accomplished ${ }^{9,10}$.

Analgesics are used routinely after various dental procedures to alleviate pain. These analgesics are divided into two groups: non-narcotic analgesics (NSAID) and narcotics (opioids). Aspirin, ibuprofen and paracetamol are the most commonly Non-Steroidal Anti- Inflammatory Drugs (NSAIDs) used to alleviate dental pain ${ }^{11}$.

Plastic wafer or chewing gum were suggested to be used immediately after orthodontic activation to reduce the pain as they tend to block the transmission of impulses via increasing blood flow in the periodontal ligament. The utilization of plastic wafer or chewing gum immediately after appliance activation is considered non-invasive, nonpharmacologic strategy to reduce pain caused by orthodontic treatment. Moreover, analgesics have side effects and may be contraindicated in patients who are hypersensitive to these medications ${ }^{12,13}$.

Polat and Karaman(2005) found a preventive preoperative, nonsymptomatic approach to control pain depending on blocking of afferent nerve impulses before reaching central nervous system ${ }^{12}$.

Thus, the present study was intended to evaluate the occurrences (onset) and intensity of pain induced after the insertion of fixed orthodontic appliances and the following activations by comparing preoperative analgesics versus non-analgesics pain management approaches (protocols).

\section{PATIENTS AND METHODS}

One hundred and fifty orthodontic patients (60 males, 90 females) were scheduled to receive fixed orthodontic treatment in the Department of Orthodontics, Faculty of Dentistry, Tanta University. They ranged from 13 to 22 years of age. They were asked to participate in this study. 
Egyptian

Orthodontic Journal

Patients' informed consent and ethical committee approval were taken. The participants must have the following exclusion criteria: systemic diseases, present utilization of analgesics, allergy or contraindication to the utilization of the study drug, extraction of teeth less than 2 weeks before bonding. The inserted appliance was partial or complete fixed in one or in both arches. Patients were divided into three groups, 50 patients each: the first group was the control group. They used acetaminophen $500 \mathrm{mg}$ orally when pain was felt (VAS $\geq 4$ ). The second group was asked to use acetaminophen $500 \mathrm{mg}$ orally30 minutes before the procedure and the third group was asked to use bite wafer (BW)(DentsplySirona Global Headquarters York/ USA)

The questionnaire given to patients was in the form of visual analogue scale (VAS).

The questionnaire was given to patients after insertion of fixed orthodontic appliance at least in one arch and asked to be completed during a week. The patients were requested to complete the scale at each time interval to represent pain severity at 4 hours, $12 \mathrm{hrs}, 24 \mathrm{hrs}, 4$ days and 7 days after initial insertion of fixed orthodontic appliance.

Patients in three groups were instructed to use analgesia if VAS was $\geq 4$.

Analgesia was in the form of acetaminophen $500 \mathrm{mg}$ orally. The time of first request to analgesia was recorded and the total paracetamol dose in the first 24 hrs was calculated.

\section{STATISTICS}

It was performed using (SPSS, version 15, SPSS Inc., Chicago, USA). Data were expressed as mean \pm SD and numbers. Mann-Whitney U-test was used for continuous data. Student's $t$-test was used for normal distributed data. $\mathrm{p}<0.05$ was considered statistically significant.

\section{RESULTS}

This study was carried out on 150 patients. Their ages ranged from 13-22 years with a mean of $18 \pm 4$ in group I, $19 \pm 3$ in group II and $17 \pm 4$ in group III. Comparison of age between three groups revealed nonsignificant difference $(\mathrm{p}>0.05)$. 
Results of this study revealed that there was a significant difference in pain intensity recorded by VAS-with the peak at night between group I and the other two groups in the first $24 \mathrm{hrs}$. Pain intensity was high in group I compared to group II and III. While, comparison between group II and group III revealed non-significant difference $(\mathrm{p}>0.05)$ (Table 1) (figure 1).

Pain intensity tended to decrease steadily with non-significant difference in all three groups after $24 \mathrm{hrs}$ till the fourth day, and by the seventh day no pain was recorded. No difference was recorded between groups II and III.

As regard to time to first analgesia, it was significantly shorter in group I compared to either group II or III. While, comparison between groups II and III revealed non-significant difference.

Analgesic consumption in group I was significantly higher than the other two groups, with non-significant difference between these two groups.

Table (1): Pain intensity

\begin{tabular}{|c|c|c|c|c|c|c|c|c|c|}
\hline & & Group I & Group II & Group III & f test & p value & p1 & p2 & p3 \\
\hline \multirow{2}{*}{4 hours } & Range & $0-6$ & $0-4$ & $0-4$ & \multirow{2}{*}{17.176} & \multirow{2}{*}{$0.001 *$} & \multirow{2}{*}{$0.001 *$} & \multirow{2}{*}{$0.001 *$} & \multirow{2}{*}{0.565} \\
\hline & Mean \pm SD & $4.04 \pm 1.64$ & $2.56 \pm 1.21$ & $2.72 \pm 1.62$ & & & & & \\
\hline \multirow{2}{*}{12 hours } & Range & $2-6$ & $0-4$ & $0-4$ & \multirow{2}{*}{41.437} & \multirow{2}{*}{$0.001 *$} & \multirow{2}{*}{$0.001^{\prime}$} & \multirow{2}{*}{$0.001 *$} & \multirow{2}{*}{0.811} \\
\hline & Mean \pm SD & $3.76 \pm 1.55$ & $1.76 \pm 0.98$ & $1.82 \pm 1.16$ & & & & & \\
\hline \multirow{2}{*}{24 hours } & Range & $0-6$ & $0-2$ & $0-2$ & \multirow{2}{*}{41.358} & \multirow{2}{*}{$0.001 *$} & \multirow{2}{*}{$0.001^{\prime}$} & \multirow{2}{*}{$0.001 *$} & \multirow{2}{*}{0.783} \\
\hline & Mean \pm SD & $2.16 \pm 1.61$ & $0.42 \pm 0.67$ & $0.48 \pm 0.71$ & & & & & \\
\hline \multirow{2}{*}{4 days } & Range & $0-1$ & $0-1$ & $0-1$ & \multirow{2}{*}{0.123} & \multirow{2}{*}{0.885} & \multirow{2}{*}{0.805} & \multirow{2}{*}{0.621} & \multirow{2}{*}{0.805} \\
\hline & Mean \pm SD & $0.22 \pm 0.42$ & $0.20 \pm 0.40$ & $0.18 \pm 0.39$ & & & & & \\
\hline \multirow{2}{*}{7 days } & Range & $0-1$ & $0-1$ & $0-1$ & \multirow{2}{*}{0.657} & \multirow{2}{*}{0.520} & \multirow{2}{*}{0.254} & \multirow{2}{*}{0.567} & \multirow{2}{*}{0.567} \\
\hline & Mean \pm SD & $0.18 \pm 0.39$ & $0.10 \pm 0.30$ & $0.14 \pm 0.35$ & & & & & \\
\hline
\end{tabular}

p1: Group I \& Group II

p2: Group I \& Group III

p3: Group II \& Group III

Volume 51 - June 2017 


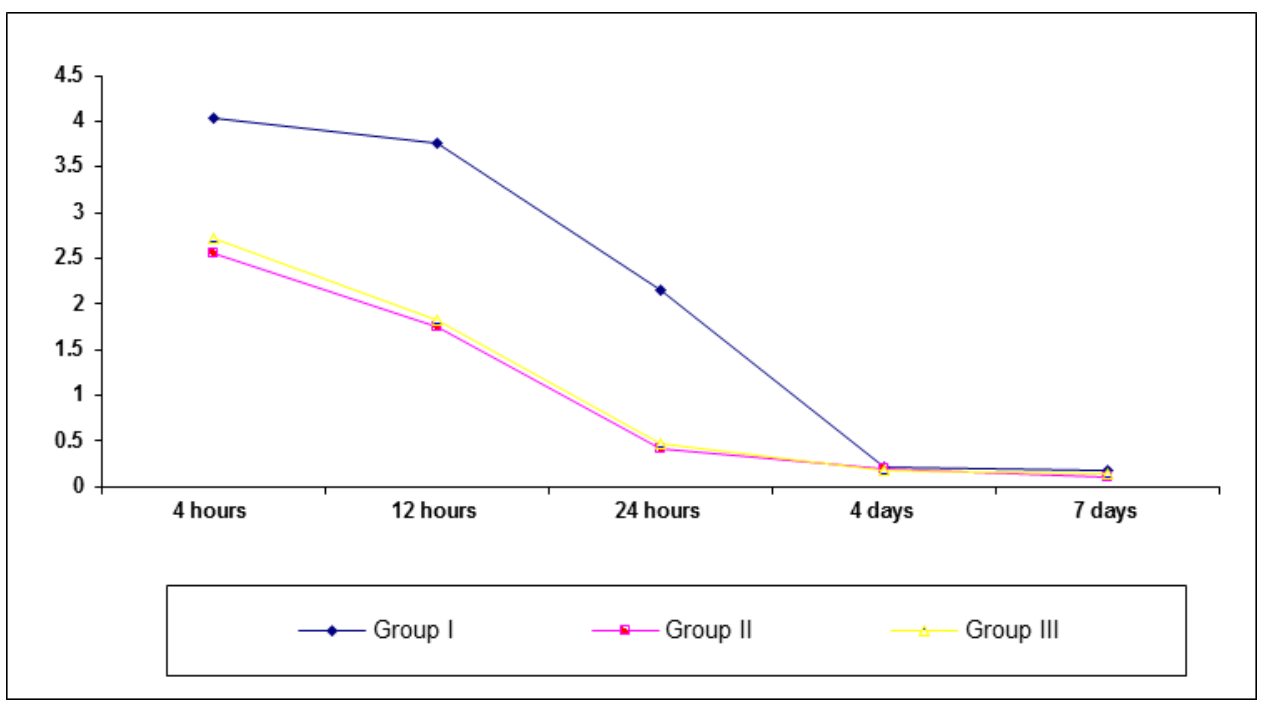

Figure 1: Course of time in postoperative pain.

Table (2): Time to first analgesic and analgesic consumption

\begin{tabular}{|l|c|c|c|c|c|c|c|c|}
\hline & Group I & Group II & Group III & f test & p value & p1 & p2 & p3 \\
\hline $\begin{array}{l}\text { Time to first } \\
\text { analgesia (hours) }\end{array}$ & $3.9 \pm 1.7$ & $5.5 \pm 3.4 *$ & $6.9 \pm 1.4 *$ & $\mathbf{8 . 9 5 1}$ & $\mathbf{0 . 0 0 1 *}$ & $\mathbf{0 . 0 0 8} *$ & $\mathbf{0 . 0 0 1 *}$ & $\mathbf{0 . 1 5 8}$ \\
\hline $\begin{array}{l}\text { Analgesic (oral } \\
\text { paracetamol) } \\
\text { consumption(mg) }\end{array}$ & $2740 \pm 252.2$ & $1490 \pm 445.9$ & $1530 \pm 545.04$ & $\mathbf{1 1 . 2 1 4}$ & $\mathbf{0 . 0 0 1 *}$ & $\mathbf{0 . 0 0 1 *}$ & $\mathbf{0 . 0 0 1 *}$ & $\mathbf{0 . 2 1 4}$ \\
\hline
\end{tabular}

Data is presented as mean \pm standard deviation

p1: Group I \& Group II

p2: Group I \& Group III

p3: Group II \& Group III

\section{DISCUSSION}

This study aimed to evaluate the onset and intensity of pain induced after the insertion of fixed orthodontic appliances, as well as to compare analgesics versus non-analgesics pain management protocols. 
Egyptian

Orthodontic Journal

Also, to evaluate the onset and intensity of pain induced after the insertion of fixed orthodontic appliances and the following activations by comparing preoperative analgesics versus non-analgesics pain management approaches.

This study was carried out on 150 patients divided into 3 groups (mean age 18 years). Each group consisted of 50 patients. These patients were asked to complete a questionnaire within a week. Visual analogue scale(VAS)used in this study is considered as a reliable and appropriate method as even children can catch the method and easily answer the questions $^{8,14}$.

Pain and discomfort are the most common complaints after application of fixed orthodontic appliance, that may lead to changes in their diet, tooth brushing and flossing and even cessation of orthodontic treatment prematurely ${ }^{3,15}$. As past studies, pain during orthodontic treatment is a combination of pressure, ischemia, inflammation and oedema ${ }^{16}$. Periodontal vasodilatation and tenderness to pain happen because of orthodontic treatment in early stages ${ }^{17}$.

In this study pain started a short time after insertion of fixed orthodontic appliance in most cases $(90 \%)$ till it reached the peak at night. These results were found in group I and III necessitating the use of either analgesic in group I or the bite wafer in group III. Also, group II demonstrated pain but its intensity was less than other two groups. These findings are in agreement with those of Kvam et $\mathrm{al}^{18}$ who found that $95 \%$ of patients reported pain from orthodontic appliance. Scheurer et $\mathrm{al}^{2}$ reported that $94 \%$ of their patients experienced pain or discomfort during the first $24 \mathrm{~h}$. Also, results found by Wilson et $\mathrm{al}^{27}$, Ngan et $\mathrm{al}^{14,19}$, Jones and Chan; ${ }^{5}$ go in line with those of $\mathrm{Kvam}^{18}$ and Scheurer ${ }^{2}$.

Many studies found that preoperative analgesics can control or decrease inflammatory response caused by orthodontic treatment as prostaglandin is not produced before inflammatory reaction begins. Effect of preoperative ibuprofen was the only analgesic investigated in many studies before insertion of archwire ${ }^{20}$. Law et $\mathrm{al}^{21}$ found in their study that preoperative use of ibuprofen showed less pain during chewing 
2 hours after orthodontic separator application than in patients took postoperative ibuprofen or placebo. Dionne and Cooper ${ }^{22}$ and Jackson et $\mathrm{al}^{23}$ and Bernhart et $\mathrm{al}^{20}$ also found that preoperative anti-inflammatory effect of analgesics may delay the severity and onset of pain. They added that preoperative mechanism of ibuprofen is that prostaglandin synthesis in peripheral tissues are blocked leading to analgesic effect, and when ibuprofen is taken postoperatively it gives less effect than when taken preoperatively. These results go in line with those of the present study.

Since NSAIDs have many adverse side effects as bleeding disorder, gastric or duodenal ulceration; asthma and allergy, hypertension, renal insufficiency, congestive heart problems and atherosclerosis, this study preferred the use of acetaminophen to avoid these effects. Acetaminophen is a para-aminophenol derivative that has analgesic and antipyretic effect $^{12,22}$. Polat and Karaman; ${ }^{12}$ used analgesic like flurbiprofen and acetaminophen with the classical drugs to reduce adverse side effects of NSAIDs in their study to control pain during fixed orthodontic appliance therapy. They concluded that orthodontic pain can be relieved by using acetaminophen. They were in agreement with this study as acetaminophen has the same effect of other efficient analgesics with minor side effects. Kehoe et $\mathrm{al}^{24}$ in their work reported that ibuprofen and acetaminophen gave an inhibitory effect on the synthesis of prostaglandin $\mathrm{E}$ in periodontal ligament but the rate of tooth movement was decreased significantly by using ibuprofen. While, tooth movement rate was the same for acetaminophen and control groups.

Most of patients after 24-48 h experienced low level of pain, except for few number of patients who had pain for a more time period. This pain was decreased till it tailed off toward sixth or seventh day. These results are in agreement with those found by White $;{ }^{7}$, Sinclair et al; ${ }^{25}$, Kvam et al; ${ }^{26}$, Wilson et al; ${ }^{27}$, Negan et al; ${ }^{19,14}$, Brown and Moerenhout; ${ }^{28}$ and Jones and Chan; 5 . This tailing off can be due to proprioceptive capacity loss 4 days after application of fixed orthodontic appliance. 
Egyptian

Orthodontic Journal

Analgesic consumption was an important pain assessment method used in this study (Table 2). The recommended dose of analgesic was oral acetaminophen $500 \mathrm{mg} 30$ minutes before orthodontic procedure. As regard to analgesic consumption, results of this study revealed that analgesic consumption was higher in group I than in group II and III, and patients in group III consumed more acetaminophen than those in group II, with the need for analgesics was diminished by the day 6-7 for all groups. So, a positive correlation was found between pain or discomfort and analgesic demand. These results go in line with those found by Negan et al $;{ }^{14}$ who reported that no need for extra dose of analgesics after administration of one dose of analgesic directly after insertion of orthodontic appliance. Also Jones; ${ }^{29}$ found a positive relation between analgesic utilization or consumption and pain with the need for analgesics was stopped by the third day.

In contrast, Jones and Chan; ${ }^{5}$ analgesic consumption after insertion of the first arch wire was not affected by degree of pain. They added that there is an individual variation in analgesic need, in that some patients preferred to take analgesics to prevent pain before going to bed, others were keen not to take any medications and they concluded that analgesic consumption gives only a truly coarse evaluation of pain reaction.

Feinmann et al; ${ }^{30}$ results were not in agreement with this study as they found a relation between analgesic consumption and anxiety. They reported that by reducing severity of pain and analgesic consumption, anxiety can be reduced.

\section{CONCLUSION}

According to this study we can conclude that either preoperative analgesia or bite wafer can effectively relief post-operative pain during orthodontic treatment.

\section{REFERENCES}

1- O'Connor PJ. Patients' perception before, during and after orthodontic treatment. J Clin Orthod. 2000; 34(10):591-2. 
2- Scheurer PA, Firestone AR and Burgin WB. Perception of pain as a result of orthodontic treatment with fixed appliances. Eur J Orthod. 1996; (18):349-57.

3- Krishnan V. Orthodontic pain: from the causes to management- a review. Eur J Orthod. 2007; 29 (2):170-9.

4- Erdinc AM, Dincer B. Perception of pain during orthodontic treatment with fixed appliances. Eur J Orthod. 2004; 26 (1):79-85.

5- Jones $\mathrm{M}$, Chan $\mathrm{C}$. The pain and discomfort experienced durig orthodontic treatment: a randomized controlled clinical trial of two initial aligning arch wires. Am J Orthod Dentofac Orthop. 1992; 102(4):373-81.

6- Fernandes LM, Ogaard B, Skoglund L. Pain and discomfort experienced after placement of a conventional or a superelastic NiTi aligning archwire. A randomized clinical trial. J Orofac Orthop. 1998; 59(6):331-9.

7- White L. Pain and cooperation in orthodontic treatment. J Clin Orthod. 1984; 18:572-5.

8- Oliver RG, Knapman YM. Attitudes to orthodontic treatment. Br J Orthod. 1985; 12:179-88.

9- Roth P and Thrash WJ. Effect of transcutaneous electrical stimulation for controlling pain associated with orthodontic tooth movement. Am J Orthod Dentofac Orthop.1986; 90: 132-8.

10- Marie SS, Powers M, Sheridan JJ. Vibratory stimulation as a method of reducing pain after orthodontic appliance adjustment. J Clin Orthod. 2003; 37(4):205, 8; 203-4.

11- Shenoy N, Shetty S, Ahmed J and Shenoy A. The pain management in orthodontics. Journal of Clinical and Diagnostic Research. 2013, 7(6):1258-60.

12- Polat $\mathrm{O}$ and Karaman A. Pain control during fixed orthodontic appliance therapy. Angle Orthod. 2005; 75(2):214-9. 
13- Lim H, Lew K and Tay D. A clinical investigation of the efficacy of low level laser therapy in reducing orthodontic post adjustment pain. Am J Orthod Dentofac Orthop. 1995;108:614-22.

14- Negan P, Wilson S, Shanfeld J ndAmini H. The effect of ibuprofen on the level of discomfort on patients undergoing orthodontic treatment. Am J Orthod Dentofac Orthop. 1994;106:88-95.

15- Sergl HG, Klages U and Zentner A. Pain and discomfort during orthodontic treatment: causative factors and effects on compliance. Am J Orthod Dentofac Orthop.1998;114:684-91.

16- Weiss DD, Carver DM. Transcutaneous electrical neural stimulation for pain control. J Clin Orthod. 1994;28:670-1.

17- Davidovitch Z and Shanfield J. Biomechanical aspects of orthodontic tooth movement: cyclic nucleotide and prostaglandin concentration in tissue surrounding orthodontically treated teeth in vivo. Am J Orthod Dentofac Orthop.1986;90:139-48.

18- Kvam E, Gjerder N, Bondevik O. Traumatic ulcers and pain during orthodontic treatment. Community Dentistry and Oral Epidemiology $1987 ; 15: 104-7$.

19- Negan P, Kess B and Wilson S. Perception of discomfort by patients undergoing orthodontic treatment. Am J Orthod Dentofac Orthop. 1989; 96: 47-53.

20- Bernhardt MK, Southard KA, Batterson KD, Logan HL, Baker KA and Jacobsen JR. The effect of preemptive and/or ibuprofen therapy for orthodontic pain. Am J Orthod Dentofac Orthop.2001; 120(1):20-7.

21- Law SLS, Southard KS, Law AS, Logan HL and Jakobsen JR. An evaluation of postoperative ibuprofen treatment of pain associated with orthodontic separator placement. Am J Orthod Dentofac Orthop.2000; 118: 629-35.

22- Dionne RA and Cooper S. Evaluation of preoperative ibuprofen for postoperative pain after removal of third molars. Oral Surg Oral Med Oral Pathol Oral Radiol Endod. 1978; 45:851-6. 
Egyptian

Orthodontic Journal

23- Jackson D, Moore P and Hargreaves K. Postoperative nonsteroidal anti-inflammatory medication for the prevention of postoperative dental pain. J Am Dent Assoc.1989; 119:641-7.

24- Kehoe MJ, Cohen SM, Zarrinnia K and Cowan A. The effect of acetaminophen, ibuprofen and misoprostol on prostaglandin E2 synthesis and the degree and rate of orthodontic tooth movement. Angle Orthod.1996; 66:339-350.

25-Sinclair P, Cannito M, GoatesL, Solomos L, Alexander C. Patients responses to lingual appliances. J Clin Orthod. 1986; 20:396-404.

26- Kvam E, Bondevik $\mathrm{O}$ and Gjerdet N. Traumatic ulcers and pain in adults during orthodontic treatment. Community Dentistry and Oral Epidemiology. 1989; 17:154-7.

27- Wilson S, Negan P, Kess B. Time course of the discomfort in young patients undergoing orthodontic treatment. Paediatr Dent 1989; 11:107-10.

28- Brown D, Moerenhout R. The pain experience and psychological adjustment to orthodontic treatment of preadolescents, adolescents and adults. Am J Orthod Dento fac Orthop.1991;100:349-56.

29- Jones M. An investigation into the initial discomfort caused by placement of an archwire. Eur J Orthod. 1984; 6:48-54.

30- Feinmann C, Ong M, Harvey W, Harris M. Phychological factors influencing post-operative pain and analgesic consumption. British Journal of Oral and Maxillo-Facial Surgery. 1987; 25: 285-292. 